Dialectologia 18 (2017), 73-94.

ISSN: 2013-2247

Received 16 March 2015.

Accepted 5 July 2015.

\title{
VOCABULARIO PESQUERO DEL NORTE DE MARRUECOS. UNA ENCRUCIJADA MEDITERRÁNEA
}

\author{
Amina NACIRI-AzZOUZ ${ }^{1}$ \\ Universidad de Zaragoza* \\ anaciri@unizar.es
}

\section{Resumen}

Este artículo contiene un estudio de léxico dialectal que incluye un análisis de la jerga de los pescadores artesanales de dos puertos situados en las regiones de Jbala y Ghomara (norte de Marruecos). Se analizan los ictiónimos más peculiares de la región y se presenta un glosario con vocabulario técnico, además se presta especial atención a los fenómenos y rasgos lingüísticos que lo caracterizan. Para ello, se analiza un corpus de más de 60 minutos, grabado en marzo de 2014, en el que participaron varios pescadores de entre 30 y 70 años. El vocabulario pesquero de esta región es un vocabulario heterogéneo debido al continuo contacto lingüístico entre los pescadores del Mediterráneo, siendo su principal característica la presencia de préstamos lingüísticos desde varias lenguas europeas y sus consiguientes adaptaciones al árabe marroquí de la región, tanto a nivel fonético-fonológico como morfológico y semántico.

\section{Palabras clave}

árabe marroquí, léxico dialectal, jerga de los pescadores, ictionimia, préstamo lingüístico

\footnotetext{
${ }^{1}$ Becaria FPI del Ministerio de Economía y Competitividad (ref. BES-2012-055959). Me gustaría agradecer a Federico Corriente y Ángeles Vicente sus comentarios. También indicar que parte de los resultados de este artículo han sido presentados en el congreso internacional: Lenguas, memorias y lecturas de la alteridad: Jbala, Ghomara y Rif (norte de Marruecos), celebrado en la Universidad de Zaragoza los días 8, 9 y 10 de septiembre de 2014.

* Campus San Francisco, Facultad de Filosofía y Letras. Calle Pedro Cerbuna 12, 50009 Zaragoza-España.
} 


\section{FISHING LEXICON OF NORTHERN MOROCCO. A MEDITERRANEAN CROSSROADS}

\section{Abstract}

This article offers a study of dialectal lexicon including the craftal fishers' jargon from the two harbours of Jbala and Ghomara (Northern Morocco). The more characteristic ichthionyms are therein listed and a glossary of technical terms is presented. Additionally, particular attention has been paid to the linguistic phenomena and features that characterize this lexicon. In order to do this, a corpus of more than 60 minutes, recorded in March 2014, has been analysed, with the participation of several fishers between 30 and 70 years old. The fishing vocabulary of this region is no doubt heterogeneous, due to continuous language contact between Mediterranean fishermen. Its main feature is the presence of loanwords from several European languages and their ensuing adaptation to local Moroccan Arabic, on most language structure levels: phonetic-phonemic, morphological and semantic.

\section{Keywords}

Moroccan Arabic, dialectal lexicon, fishers' jargon, ichthionymy, loanwords

\section{Introducción}

La pesca artesanal es una de las actividades más desarrolladas en la costa mediterránea marroquí siendo el motor económico de numerosos pueblos y ciudades, como son aquellos de las regiones de Jbala y Ghomara. ${ }^{2}$

En este artículo se presenta una breve aproximación al vocabulario pesquero de dos puertos que ejemplifican las diferencias que existen entre los puertos del norte de Marruecos. Targha es un pequeño pueblo ghomarí que hasta hace dos años era de muy difícil acceso y cuyos pescadores practican una pesca casi de subsistencia. ${ }^{3}$ Por el contrario, M'diq-Rincón ${ }^{4}$ es una ciudad en continuo crecimiento que se articula alrededor del puerto. Si bien entre ambas localizaciones hay una distancia de 77 kilómetros, son notables las diferencias en la práctica de la pesca y la jerga de sus

\footnotetext{
${ }^{2}$ En la actualidad, Jbala y Ghomara son etnónimos que agrupan las cabilas situadas entre el Estrecho de Gibraltar y el Corredor de Taza (cf. Vignez-Zunz (1995) y Camps \& Vignez-Zunz (1998)).

${ }^{3}$ En 2012 se inauguró la Carretera Nacional 16 que atraviesa toda la región del Rif comunicando numerosas regiones antes aisladas.

${ }^{4}$ De aquí en adelante, se empleará la forma Rincón ya que es la más común en la región.
} 
pescadores. Aquí se ha estudiado en conjunto dejando a un lado las variantes dialectales que naturalmente inciden en el léxico pero sobre todo a nivel fonético-fonológico. ${ }^{5}$

El estudio del léxico pesquero puede aportar información muy interesante sobre el desarrollo de la actividad pesquera en la costa mediterránea marroquí, y del Mediterráneo en general, ya que es un testimonio más de la historia del Mare Nostrum. Se trata de un vocabulario heterogéneo producto del contacto lingüístico entre los pescadores de la cuenca mediterránea cuyo mayor exponente es el préstamo lingüístico.

En las últimas décadas se han llevado a cabo numerosos proyectos de colaboración en el marco de la Organización de las Naciones Unidas para la Alimentación y la Agricultura (FAO) que ofrecen datos cuantitativos sobre la pesca artesanal en la región. ${ }^{6}$ Estos datos son muy útiles a la hora de determinar su importancia y, por consiguiente, la pertinencia de estudios desde diferentes disciplinas. Por ello, se echa en falta la colaboración de dialectólogos para complementar los datos publicados por la FAO ayudando a poner en valor el patrimonio material e inmaterial de los pescadores del sur del Mediterráneo.

\footnotetext{
${ }^{5}$ Siempre que se ha creído necesario, se han marcado estas diferencias. Asimismo, debido a la inestabilidad de la duración vocálica y el debate en torno a la misma en los dialectos del noroeste de Marruecos no se ha marcado en la transcripción.

${ }^{6}$ El interés de la FAO por la pesca no es reciente, desde su fundación en 1945 esta organización ha presentado informes de esta actividad en el Magreb. En el caso de Marruecos ya tenemos informes publicados desde la década de los cincuenta.

En este marco, es pertinente destacar dos proyectos que han sido de gran utilidad a la hora de abordar este tema: a) el primero es el Catalogue des engins de pêche au Maroc (Roullot et al. 1984) que presenta de una manera ordenada las técnicas de pesca más comunes en Marruecos, incluso presentando las diferentes partes de redes que se utilizan, etc.; b) el segundo es el proyecto COPEMED y sus continuaciones, COPEMED II y ArtFimed, financiados por la FAO, la Agencia Española de Cooperación Internacional, la DG des Pêches de la Communauté Européenne y la Secretaría General de Pesca Marítima, las dos últimas en las ampliaciones del proyecto. Uno de los resultados de este proyecto, además de los informes y publicaciones, ha sido una base de datos interactiva con datos estadísticos de todo el Mediterráneo occidental, tanto su cuenca norte como sur. En el caso de Marruecos, hay una breve descripción de todos los embarcaderos y puertos de la costa mediterránea que se presentan en mapas que arrojan datos muy interesantes sobre la pesca artesanal: pesca por temporadas, artes de pesca, número de embarcaciones, marineros activos, etc. [En línea] Consultado el 24 de octubre de 2014: http://www.faocopemed.org/old_copemed/reports/artfish/artfiweb/mar_main.html
} 


\section{Recogida de datos: Targha y Rincón ${ }^{7}$}

La fuente de este estudio ha sido un corpus de más de 60 minutos grabado en marzo de 2014, se utilizaron entrevistas semiestructuradas para recoger la información relativa a los nombres de los peces y los aparejos de las embarcaciones.

La primera visita fue al embarcadero de Targha, una antigua ciudad medieval que fue perdiendo prestigio por las incursiones cristianas a partir del siglo XV (Bazzana et al. 1991: 307-329). En el siglo XVI, León el Africano ya señalaba su decadencia a causa de la invasión, donde además mencionaba la pesca como actividad principal de sus habitantes:

... et les habitants (au moins la plus grande partie) son pêcheurs, qui salent leur poisson, puis le vendent aux marchands montagnards, qui le transportent à cent mille de là du côté du midi [...] mais depuis que les Portugais minent le pied aux cités [...] elle a commença fort à manquer en honnêteté accoutumée et habitation (León el Africano 1830: 502).

En la administración actual del reino alauita, Targha pertenece a la comuna rural de Tizgane, pronvincia de Chauen, región Tánger-Tetuán. Se trata de un pequeño pueblo de la cabila Bni Zyāt de Ghomara, situado aproximadamente a 60 kilómetros de Tetuán. Cuenta con alrededor de 25 embarcaciones depositadas sobre la arena y unos 70 marineros según los datos de la FAO. ${ }^{8}$

En este pequeño embarcadero se grabó a dos pescadores hermanos: el mayor de 50 años y el menor de 35 años. El hermano mayor había trabajado siempre en Targha desarrollando diferentes actividades dentro del sector pesquero. En el momento de la

\footnotetext{
${ }^{7}$ Estos datos fueron recogidos con la colaboración de Ángeles Vicente y Araceli González Vázquez en el marco del proyecto La montagne et ses savoirs (Rif occidental, Maroc). Programme International de Coopération Scientifique (PICS), financiado por el Centre national de la recherche scientifique (Francia) y el Centre National pour la Recherche Scientifique et Technique (Marruecos). También agradecer la preciada generosidad y paciencia de los pescadores de Targha y Rincón que muy amablemente accedieron a compartir con nosotras su conocimiento de la mar, dejando a un lado sus labores e incluso continuando con ellas.

8 FAO COPEMED. [En línea] consultado el 24 de octubre de 2014: http://www.faocopemed.org/old_copemed/reports/artfish/artfiweb/mar/ports/martardp2.html.
} 
entrevista, el hermano pequeño trabajaba en Targha pero en varias ocasiones había faenado en buques pesqueros a lo largo del Atlántico.

Los pescadores señalaron que la pesca artesanal es, junto a la agricultura, una de las principales actividades del pueblo, qarya. No obstante, se lamentaron de que cada vez haya menos jóvenes dispuestos a seguir los pasos de sus padres y abuelos. En efecto, muchos de estos jóvenes prefieren embarcarse en los buques industriales a pesar de que cada vez más se intenta cubrir las deficiencias del sector: en Targha, por ejemplo, se construyó una lonja que lleva operativa aproximadamente dos años en un intento de regular y mejorar las condiciones de los pescadores aunque éstos no mencionaron la construcción de un puerto, lo que por ejemplo ayudaría a proteger sus embarcaciones.

En cambio, Rincón es una ciudad situada a $15 \mathrm{~km}$ de Tetuán, poblada por gentes de diferentes orígenes gracias a los intercambios comerciales con Ceuta. En esta ciudad hay un puerto propiamente dicho construido en la década de los setenta. Se trata de un puerto grande, con numerosos servicios y zonas de ocio. Rincón es una de las ciudades más explotadas por el turismo y uno de sus reclamos es el puerto. Hasta el momento, el vertiginoso desarrollo del turismo no ha suprimido esta actividad que se mantiene como motor económico de la ciudad, contando con más de un centenar de embarcaciones.

En esta pequeña ciudad se grabó a tres grupos de pescadores, tres o cuatro pescadores por cada grupo, y de edades comprendidas entre los 30 y los 70 años, todos ellos dedicados al oficio de la pesca artesanal.

En esta visita se ha podido comprobar que la zona del puerto reservada a la pesca tiene suficiente infraestructura para su normal desarrollo, así como todo el material en diferentes tiendas especializadas que sirven para proveer todos los pescadores de la región, incluidos los de Targha. 


\section{Léxico pesquero: Ictionimia}

La complejidad del vocabulario ictionímico radica principalmente en su sinonimia, polisemia y homonimia (Anaya Revuelta 1999) ya que es un vocabulario muy heterogéneo, por lo que hay múltiples aproximaciones para su estudio.

Desde la semántica hay trabajos centrados en la motivación y la creación léxica en los diferentes niveles de lengua (González García 2008: 117-401); otros que lo abordan desde la semántica cognitiva, especialmente interesante, donde se define la metáfora como un "mecanismo para delimitar y categorizar conceptos no directamente accesibles" (Pamies 2010: 34). Un mecanismo muy presente en el campo ictionímico "que es en su mayor parte metafórico y sus imágenes se inspiran en unos pocos dominios conceptuales, esencialmente animales, profesiones, plantas, anatomía humana y artefactos construidos por el hombre, por lo que nuestra visión del universo marino se realiza "a través" de nuestra experiencia del entorno terrestre" (Pamies 2010: 34). Pero principalmente se ha estudiado desde la lexicografía, indagando en los orígenes de los diferentes vocablos que lo componen.

Desde todas estas aproximaciones, para estudiar la ictionimia marroquí se debe tener muy en cuenta el desarrollo de la ictionimia española, especialmente la andaluza, un área muy prolífica en el seno de la dialectología y la geografía lingüística del español (Alvar 1970, Mondéjar 1989, etc.).

En este contexto, disponemos de una herramienta de gran utilidad, la Base de Datos Terminológicos y de Identificación de Especies Pesqueras de las Costas de Andalucía, bajo el acrónimo ICTIOTERM. ${ }^{9}$ Ésta reúne resultados de encuestas recientes realizadas por todos los puertos andaluces y a su vez se complementa con datos de la llamada "Bibliografía ictionímica de Andalucía": un compendio de obras que recogen nombres de peces publicadas en un período que comienza en el siglo XVII y finaliza con

\footnotetext{
${ }^{9}$ Desarrollada por el Instituto de Ciencias Marinas de Andalucía, Consejo Superior de Investigaciones Científicas (CSIC), y el Departamento de Filología y Traducción, Universidad Pablo de Olavide en Sevilla: http://www.ictioterm.es/index.php.
} 
el Boletín del Estado de 2012 donde se especifican las denominaciones comerciales en España, pero la mayoría de estas obras pertenecen a las ciencias naturales. ${ }^{10}$

\subsection{Ictionimia marroquí}

El interés por este campo léxico en Marruecos no es reciente. En el periodo colonial, la pesca artesanal fue una de las actividades profesionales que despertaron el interés de los investigadores. Uno de los primeros estudios sobre esta actividad en el norte de Marruecos es de A. Joly (1912), en su artículo sobre las industrias de Tetuán no podían faltar las industrias del mar: la pesca y la construcción de embarcaciones. En principio, la intención de su autora no fue presentar un trabajo lingüístico, más bien presenta de manera sucinta el funcionamiento de esta actividad en Tetuán y alrededores pero incluye los nombres de los peces más comunes y otros términos técnicos referidos a las embarcaciones. En este artículo se observa la importancia de los ghomara en las industrias marineras donde cuatro maestros de esta región se encargaban de la construcción de embarcaciones para el poder jalifiano y español (Joly 1912: 235).

A este periodo pertenecen los primeros estudios que prestan atención al vocabulario pesquero en bereber desmontando la idea de que los autóctonos son reacios al mar (Laoust 1923; Montagne 1923, 1924).

Sin olvidar las dos obras de Brunot, una dedicada al estudio de las tradiciones relacionadas con el mar, un estudio con un tinte colonial claro (Brunot 1920a); y un estudio del vocabulario marinero de Rabat y Salé donde además se incluyen variantes comunes de Tánger y Larache (Brunot 1920b). ${ }^{11}$

Una obra que ofrece un nutrido número de ictiónimos es el diccionario de Prémare (1993-1999) ya que incluye los datos recogidos por Jean-Paul Canamas en la década de los setenta.

\footnotetext{
10 En este enlace se pueden encontrar la nómica de dichas obras: http://www.ictioterm.es/bibliografia.php.

${ }^{11}$ De esta época son los catálogos y atlas de pescados que no tienen en cuenta la lengua vernácula (cf. Belloc 1934).
} 
En esta pequeña mención a las obras que han tratado este campo léxico en Marruecos, no podía faltar la obra de Oman Giovanni (1966) que agrupa casi 400 especies detallando el nombre científico y los nombres vernáculos en diferentes puntos bañados por el Mediterráneo permitiendo ver el recorrido de los ictiónimos.

De las últimas décadas, cabe mencionar la obra de A. Lataoui (1999) que presenta un estudio general de la ictionimia marroquí a partir de datos recogidos en la región de Safi (Āsfï). Asimismo se debe reparar en los estudios centrados en los préstamos en el árabe marroquí, especialmente los hispanismos donde el vocabulario pesquero tiene una mención especial (Kaddour 2013, Guerrero 2015, etc.). ${ }^{12}$

Sin embargo, hasta ahora se puede afirmar, tal y como apuntó André Louis (1977: 35, n. 23), que aún no tenemos ninguna obra resultante de una labor de revisión y síntesis de las mencionadas en el apartado anterior y que sirva como base para futuras investigaciones cuyas aspiraciones se centren en el estudio del riquísimo vocabulario pesquero desde diferentes enfoques: como pueden ser el contacto de lenguas, la lexicología o la semántica.

En efecto, la mayoría de los términos recogidos en Targha y Rincón son un ejemplo del contacto lingüístico de los pecadores mediterráneos. De este modo, la mayoría de los términos de origen romance, que en la actualidad forman parte del vocabulario de base del léxico pesquero, llegaron a través del árabe andalusí donde los préstamos romances fueron especialmente cuantiosos en los nombres de animales y plantas, tal y como explica Federico Corriente: "From a diachronic viewpoint, R[o]m[ance] borrowings can be classified as substratal, adstratal and superstratal. Substratal romancisms were those necessarily adopted by the first generation of Arabic speakers in the Iberian Peninsula, in order to express concepts previously unknown to them, like the name of certain endemic animals and plants" (Corriente 2011: 173).

Otros términos tienen su origen en la lingua franca mediterránea, un pidgin compuesto principalmente por el italiano, el francés, el español y otras lenguas como el turco y el árabe utilizado en el Mediterráneo hasta el siglo XIX; no obstante, su difusión en Marruecos había sido menor, especialmente en el norte, por la hegemonía del

\footnotetext{
${ }^{12}$ S. Lévy (1992: 59-74) nos ofrece un estado de la cuestión completo sobre los hispanismos en el vocabulario marino pesquero en Marruecos poniendo hincapié en el contexto histórico y sociolingüístico.
} 
español y portugués (Dakhlia 2008: 243-263), lo que explica la fuerte presencia de hispanismos en el léxico pesquero; y por supuesto, términos árabes.

Así las cosas, se puede afirmar que la génesis del vocabulario pesquero del norte de Marruecos es un testimonio de la permeabilidad de la frontera mediterránea, incluso en una época marcada por las tensiones como han sido los siglos XVI, XVII y XVIII:

... la hostilidad imperante entre la Monarquía hispana, por un lado, y los sultanes otomano y marroquí, los beys de Túnez y Trípoli y el dey de Argel, por el otro, no fueron suficientes para impedir que la frontera mediterránea cumpliera uno de los objetivos que se le atribuye a toda franja fronteriza, la de convertirse en zona de intercambios (Martín Corrales 2001: 571).

Una prueba que confirma lo anterior son los términos que se emplean hoy en día en Targha y Rincón. Por un lado, los ictiónimos de origen andalusí:

buqa 'boga': del latín boca que aparece en andalusí como búqa;

šarg̉u 'sargo': del latín sargus, también un préstamos del andalusí donde ya aparece bajo la forma šárg்u (El Yaâcoubi 1996: A-66);

šral 'jurel': del diminutivo de saurus, saurellus en bajo latín, que ha dado en andalusí šuril y éste ha pasado al marroquí como el colectivo šral, empleado sobre todo en el norte aunque se ha extendido al sur (El Yaâcoubi 1996: A-68);

šțon 'anchoa': otro préstamo del andalusí, šuțún, aunque hay cierto debate sobre esta etimología (cf. El Yaâcoubi 1996: 119).

Un pescador en Targha al hablar de las anchoas recalcó que se utiliza otro término de origen bereber: lančuba. ${ }^{13}$ Pero en realidad se trata de un préstamo más reciente, seguramente del catalán anxova o portugués anchova (El Yaâcoubi 1996: A-72, Prémare et al. 1999: $\mathrm{XI} / 362-363)$.

Tras la caída de Granada en 1492, las relaciones continuaron, la llegada de moriscos castellanoparlantes entre los siglos XV y XVII reforzó el contacto lingüístico con el español, pero también continuaron las relaciones con pescadores peninsulares ya que España no cejó en su empeño de controlar la orilla mediterránea sur a pesar de los

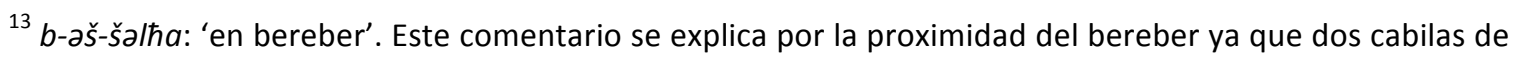
Ghomara, Bni Bu Zra y Bni Mənșūr, son aún berberófonas (cf. Behnstedt 2002).
} 
corsarios y otros problemas, es decir: "El estudio de la actividad pesquera española en el litoral norteafricano a lo largo de los siglos XVI-XVIII es el estudio de una expansión frenada" (Martín Corrales 2000: 10).

Por otro lado, hay préstamos relativamente recientes, de la época del Protectorado Español (1912-1956) donde la presencia española no deja lugar a dudas: un análisis fonético del préstamo que tenga en cuenta la evolución del español puede indicar aproximadamente cuándo se introdujo.

Ahora se puede hablar de hispanismos como čoko 'jibia, choco', documentado en español a principios del siglo XVIII; ${ }^{14}$ y kabaya 'caballa', documentado en español en el siglo XV, ${ }^{15}$ entre muchos ictiónimos (El Yaâcoubi 1996: E-162 y E-227).

En Targha también se emplea la variante kabayla donde el fonema lateral palatal del español $\Lambda$ pasa como yl, siendo más usual su paso como y o ly (Heath 1989: 89). Oman sitúa esta variante en Casablanca (Oman 1966: 203 y 204), Brunot (1920b: 121) la recoge en Rabat-Salé, Prémare et al. (1998: X/498) la sitúa en el sur de Larache pero también se emplea en el Mediterráneo.

Por último, los términos árabes, que tal y como apunta Brunot (1920b: VIII), son términos no técnicos que utilizan palabras árabes para darles un nuevo uso marino.

Por ejemplo, labroq (Prémare et al. 114, 1/195; Dozy 1927: I/74, Pabraq) 'raya': un término documentado en el siglo XIII y cuya raíz $\{$ brq $\}$ engloba la idea de relampaguear y tronar haciendo referencia a las características fisionómicas del animal: una cola a modo de látigo, la de algunas especies tiene un aguijón venenoso que causa gran dolor, y otras especies provocan sacudidas eléctricas. También se emplea de manera habitual raya, común en todo el Mediterráneo y perteneciente a la lingua franca (El Yaâcoubi 1996: E441; Prémare 1995: $\mathrm{V} / 22$ ).

Otro término de este grupo es mharqșa 'dorada': del cobre en griego, $\chi \alpha \lambda \kappa o ́ s$. Dozy recoge diferentes variantes entre las que se encuentra ћarqūș, con la acepción 'cobre quemado' (Dozy 1927: I/317). Un nombre derivado bajo la forma de un participio de verbo cuadrilítero que en marroquí tiene el siguiente esquema\{m-CaCC-a\} (Heath

\footnotetext{
14 ICTIOTERM [en línea], consultado el 12 de noviembre de 2014: http://www.ictioterm.es/nombre_vernaculo.php?nv=345.
15 ICTIOTERM [en línea], consultado 12 de noviembre de 2014: http://www.ictioterm.es/nombre_vernaculo.php?nv=182.
} 
1989: 117) en una clara alusión a la línea dorada que tiene este pez en la cabeza (Prémare et al. 1994: III/79; Oman 1966: 137).

\subsection{Algunas novedades ictionímicas}

Este apartado se centra en algunos ictiónimos muy particulares de Targha y Rincón que no han sido estudiados en profundidad en las diferentes fuentes consultadas.

a) mūl əš-šayn 'mejillón', mytilus edulis

Los pescadores de Targha señalaron este término como particular de la región de Ghomara subrayando que es desconocido en el resto de Marruecos. Siendo así que no se ha localizado bajo esta forma en ningún diccionario o estudio.

La primera posibilidad al tratar este vocablo fue pensar en un galicismo proveniente de moule. En Argelia existe el galicismo mūl recogida en Cherchell y Annaba (Oman 1966: 279b). Sin embargo, dado la escasez de galicismos en el corpus se barajan dos hipótesis:

La primera es un posible origen arabo-andalusí proveniente de las formas šayn, 'deshonra' (Corriente 1997: 299), y šay?, 'vulva'. Se trataría de una palabra compuesta formada a partir de mūl, 'poseedor/guardián de', en una clara referencia a las características fisionómicas del molusco que al poseer concha guardaría la deshonra o la vulva.

La segunda hipótesis guarda relación con la entrada məššəl, mūššəl, məššăal del diccionario de Prémare et al. (1999: XI/210) y se combina con la primera hipótesis. Este término lo localiza Canamas en la zona berberófona del Rif donde además precisa que es común en Targha. En este caso, se puede considerar un término árabe berberizado y que más tarde se ha vuelto a arabizar: *šayn o *šay? $\rightarrow$ məššal $\rightarrow$ mūl əš-šayn. Un caso opuesto sería taġzalt, 'boga': un término árabe berberizado pero que se ha extendido y se mantiene bajo esta forma en todo el norte de Marruecos: $\{\dot{g} z \mid\} \rightarrow$ tag்alt (Prémare et al. 1993: II/12). 
Sin embargo, muššal aparece en los diccionarios de andalusí, un vocablo que puede significar mejillón, vulva o almeja, y proviene del latín musculus o mitilus (Corriente 1997: 503, Simonet 1888: 13). Por consiguiente, ambas hipótesis convergen, se puede deducir que los pescadores en diferentes épocas han adoptado muššal, pero a causa de una adaptación semántica por la pérdida del origen de la palabra se haya preferido el uso de un término que en la actualidad representa algo, 'el que guarda...'.

b) lobar: pez breca, pagellus erythrinus (Oman 1966: 141; Prémare et al. 1999: XI/96)

En español el pez breca deriva del romano-andalusí *lubráyqa y éste del latín rubra, 'rojizo', por el color rojizo del pez (Corriente 2008: 387). En andalusí encontramos la forma lúbra pl. lobár (Corriente 1997: 474).

En la actualidad, este término se emplea en la costa mediterránea marroquí como un colectivo. Si bien sólo se emplea en el norte de Marruecos, se documenta su uso en otras regiones del Mediterráneo como el caso de algunos dialectos italianos: "salentino lúvaru, luvru, el napolitano lúväro, el siciliano lúvaru, etc." (Mondéjar 1989: 82), lo que permite afirmar que puede tratarse de un término común en el Mediterráneo.

Las consonantes del término, teniendo en cuenta la inestabilidad de las líquidas / y $r$, conducen también al róbalo. Lo que interesa es que en español ha existido el paso de *lobarro a 'róbalo' a causa de una asimilación por la pérdida del origen de la palabra (Mondéjar 1989: 86). En cambio, en catalán se mantiene el término llobarro. Con estas pesquisas lexicográficas, apareció 'baila', Dicentrarchus punctatus, que comparte su etimología con breca, es decir, lubáyra, pero con una evolución diferente (Corriente 2008: 368$).{ }^{16}$ Sin embargo, denomina a un pez de la misma familia que el róbalo y la lubina. Todo ello apunta a una posible relación entre ambos términos aunque, en principio, ambos proceden de dos orígenes diferentes y designan peces de distintas familias, el róbalo pertenece a la familia de los morónidos y la breca a la familia de los espáridos.

\footnotetext{
${ }^{16}$ ICTIOTERM baraja otra etimología del mozarabismo lobaira y éste del latín lupus: [En línea], consultado el 12 de noviembre de 2014: http://www.ictioterm.es/nombre_cientifico.php?nc=67.
} 
c) rmuli: (una expresión que muestra el aprecio por este pez es: rmuli țayybu w-qarrbu li, 'cocine la herrera y acérquela') ${ }^{17}$ herrera, marba, lithognathus mormyrus (Oman 1966: 145).

Prémare et al. (1995: V/215) afirma que el origen de este término lo encontramos en la denominación del español andaluz 'marmóreo'. Sin embargo, la base de datos ICTIOTERM no lo recoge. En Andalucía, la denominación más común es 'herrera' que convive con el término 'marba', del catalán marbre, más cercano semánticamente a rmuli. Aunque no se emplea en el español actual, tanto Prémare como Oman (1966: 145) muestran que es común en el Mediterráneo, así tenemos marmora y mórmora en italiano y marmūra en Líbano.

Lo llamativo de este ictiónimo es que en marroquí se ha perdido la relación entre rmuli y el mármol. En este dialecto existe la tendencia de la caída de la vocal de primera sílaba generalmente en préstamos del español y francés (Heath 1989: 83). Éste es particular ya que no cae únicamente la vocal, sino también el fonema nasal $m$ acompañado de lambdacismo de /r/ $\rightarrow / \mathrm{l} /:{ }^{*}$ mormyro $\rightarrow{ }^{*}$ mrmyro $\rightarrow{ }^{*}$ rmyro $\rightarrow$ rmuūli.

El resultado es una transferencia semántica y de aquí que rmuli se relacione con la arena, rmal en árabe marroquí. Además los pescadores al describirlo destacan que es un pez que habita los fondos marinos, arenas y fango.

d) montanyo: cangrejo ermitaño (Prémare et al. 1999: XI/279)

Un término recogido en Rincón al explicar un informante los diferentes cebos que se utilizan para pescar en la región. La descripción corresponde con el cangrejo ermitaño utilizado como cebo para la pesca de la dorada, entre otras especies.

Prémare et al. (1999: XI/279) habla de un hápax cuyo origen procede del argot de los pescadores andaluces, 'montañés' o 'montañoso'. No obstante, en la base de datos ICTIOTERM no aparece ninguna de las denominaciones, ni siquiera alguna relacionada con la montaña.

\footnotetext{
${ }^{17}$ Otra variante de este refrán: وفَرْبُولي افْليه الزُمولي، (al-BūYnānī 2003: 472). Transcripción: rmūli, qlīh uqarbu li [sic]. Traducción: Fríe la herrera y acérquela.
} 
La primera opción es pensar en la propia creatividad de los hablantes que se sirven de una palabra española, en este caso montaña, para referirse a una especie de cangrejo que utiliza una concha ajena para cubrirse, de ahí la evocación a la montaña. Por esta razón cabría preguntarse por qué no se ha utilizado una denominación autóctona y se ha preferido 'montaña' que además no es habitual en Marruecos. Quizá la respuesta sea la propia consciencia de los pescadores que ven en el español la lengua del mar, y además aparece el morfema masculino español o que denota cierto uso avanzado de la lengua.

Es una simple reflexión, no hay referencias a este término, ni siquiera se ha podido comprobar que esto mismo suceda con otros nombres de peces ya que se suele recurrir a términos de la lengua autóctona para formar ictiónimos nuevos.

Una última posibilidad es que haya pasado de ermitaño a montanyo, siendo el primer término más desconocido y al no comprender su significado se haya recurrido por analogía a un término más conocido.

\section{Vocabulario técnico}

Dejando a un lado la ictionimia, esta sección se va a ocupar de un vocabulario más técnico, concretamente el que tiene relación con las embarcaciones y sus aparejos.

Como se ha comentado en la introducción, tenemos numerosos estudios muy detallados sobre las diferentes técnicas de pesca que se utilizan en la mayoría de los puntos de la costa mediterránea marroquí, estudios apoyados por la FAO y que presentan sus resultados a través de informes técnicos y publicaciones académicas ( $v$. nota 4).

El vocabulario técnico es mucho más uniforme que el ictionímico dado que la inmensa mayoría de los términos utilizados son préstamos directos del español que sufren algunos cambios para adaptarse a la fonética del árabe marroquí de la región (cf. Heath 1989).

Esta primera fase de la investigación se ha centrado únicamente en el análisis de los términos relacionados con las embarcaciones y los diferentes aparejos de los que se 
sirven los pescadores que se presentan en este breve glosario con algunas anotaciones lingüísticas y otra información facilitada por los pescadores de Targha y Rincón.

\subsection{Glosario}

buġarat 'boguera': arte de enmalle que le debe su nombre a la boga. En español se añade el sufijo -era al pez que más se recoge con un tipo de red y se da ese nombre a la técnica de pesca, como boguera por la boga. En cambio, en árabe marroquí se ha optado por el femenino plural, un fenómeno habitual como ya señalara Heath (1989: 134): “(In northern Morocco, Sp[anish] borrowings with FSg /-a/ take regular FPI /-at/ [...] and is especially common with long or otherwise unusual nouns that do not fit into an ablaut pattern". Se puede justificar este uso no sólo por la estructura morfológica sino también por una adaptación semántica que se explica por la tendencia del uso de colectivos para denominar a los peces -šțon, sardin, šral, etc. - y así se emplea en plural la técnica para pescarlos en conjunto.

čeqo: cerco de cada uno de los paños de una red de pesca. Encontramos una realización chicheante que sólo se explicaría por dos razones: a) la primera es pensar en un préstamo antiguo por la realización chicheante de la fricativa interdental sonora; b) o bien, un préstamo del italiano relacionado con el verbo cercare que aunque en la actualidad es 'buscar', en su origen deriva del latín circare 'andare intorno', cercar. ${ }^{18}$

čnabal pl. 'chambel': tipo de pesca de palangre. En español, por un proceso metonímico, ha pasado a denominar el tipo de pesca y no el sedal (González García 2008: 251).

farša 'paral': madera que sirve para deslizar las embarcaciones al mar. En árabe marroquí, es un nombre polisémico y uno de sus usos es marinero ya que la mayoría de sus acepciones tienen relación con el hecho de extender algo como una cama, una esterilla, etc. (cf. Brunot 1920b: 100; Marçais 1911: 411; Prémare et al. 1998: 63).

faršiyya: una hilera de boyas. Un término utilizado comúnmente para construcciones de madera. En este caso, aunque las boyas que se utilizan en la actualidad son de polietileno, antiguamente eran de corcho (Prémare et al. 1998: 67;

\footnotetext{
${ }^{18}$ Treccani, L'Enciclopedia Italiana [en línea]: http://www.treccani.it/vocabolario/cercare/.
} 
Brunot 1920b: 100). Alfarje es un arabismo que proviene de esta misma palabra y una de sus acepciones es un tipo de techo de madera (Corriente 1997: 217).

fluka pl. flayək o flukat 'falúa': ${ }^{19}$ los criterios para diferenciar las falúas de otras embarcaciones son diferentes en Targha y Rincón. Los pescadores de Rincón se centran en el tamaño siendo la falúa la de menor tamaño, mientras que los pescadores de la zona de Targha se refieren a las embarcaciones con la proa y la popa en pico como falúa y las demás, con la popa recta, como barku o šabbak, entre otras denominaciones.

kabu 'cabo': un préstamo muy reciente que no hemos localizado en ninguna fuente consultada.

karrasa 'nasa': un aparejo que se emplea para pescar crustáceos. En Targha tiene forma de cesto. Este vocablo puede derivar de carroza en español pero no corresponde a la carroza marinera que es una lona que cubre las embarcaciones para protegerlas. En árabe no se ha localizado un equivalente aunque corresponde al esquema de un nombre de instrumente $\left\{\mathrm{C} ə \mathrm{CC}^{\mathrm{C}} \mathrm{C} a\right\}$.

ladorat: arte de enmalle que le debe su nombre a la dorada (v. bugarat).

lastro pl. lašțriwat 'rastro': aunque es un hispanismo que normalmente se ha atribuido a lastro (El Yaâcoubi E-308; Brunot 1920b: 129), teniendo en cuenta la inestabilidad de las líquidas en los préstamos marroquíes y su significado, se acercaría más a rastro que a lastro (Heath 1989: 85-90). En este término también llama la atención la formación del plural que aunque sea común el uso del alomorfo -wat en palabras acabadas en -o (Heath 1989: 135), la apofonía no se explica. Heath (1989: 78) sólo presenta un ejemplo de plural apofónico y evidentemente sin el sufijo. La única hipótesis que lo explicaría es un doble plural: apofónico y con sufijo.

lampara 'barco lucero': un bote cualquiera que incorpora lámparas para atraer a los peces por las noches, se suele utilizar con la técnica del cerco. No se ha localizado un equivalente en español aunque en francés se utiliza la expresión pêche au lamparo para esta técnica de pesca y en italiano lámpara.

marberat 'melvera': arte de deriva para pescar melvas (v. bugarat y ladorat). maxțaf 'ancla' (Dozy 1927: I/384).

\footnotetext{
${ }^{19}$ Para la etimología, cf. Corriente (1997: 467) y Kahane et al. (1953: 56-62).
} 
monete 'molinete': una polea que sirve para levar ancla o cualquier cabo de una embarcación. El paso de molinete a monete resulta curioso puesto que generalmente las caídas de vocal, que en ocasiones incluye ataque silábico, suele ser de primera sílaba (v. rmuli). En cambio, aquí cae la segunda sílaba por asimilación lo que hace suponer que no se trata de un préstamo reciente ya que no hay una adaptación fonética que mantenga todos los segmentos del español.

moțor pl. mwațar 'motor' (El Yaacoubi E-370): tiene un plural fracto, común en algunos préstamos (Heath 1989: 137).

murixas o wadnin pl. 'alas': lateral de las embarcaciones (Targha). Un calco semántico del español orejas, si bien los pescadores en Targha también utilizan el hispanismo murixas en un posible intento de arabizar el término añadiendo mūl con el sentido de quien posee algo que junto a rixas pasa a murixas.

Otra posibilidad es que haga referencia a la amura: parte donde empiezan a estrecharse las embarcaciones para dar lugar a la proa. Sin embargo, las alas u orejas es una formación semántica antropomórfica que hace referencia a las alas de las embarcaciones donde estarían las orejas o las alas y de ahí que en Targha y Rincón se emplee wadnīn.

palangrat 'palangre': tendencia de uso de plural (Brunot 1920b: 12).

paleța 'paleta' (El Yaâcoubi 1996: E-34; Brunot 1920b: 11).

parexat 'pareja': un barco de arrastre (El Yaâcoubi 1996: E-43; Brunot 1920b: 6). En ocasiones, los pescadores realizan el plural parexat para referirse a una sola embarcación. Este uso se puede explicar por una posible adaptación semántica por la función de la embarcación: uso de dos puertas para orientar la red y dos embarcaciones de arrastre.

paţi țonaž: embarcación de pequeño tonelaje. Un galicismo recogido en Rincón, petit tonnage 'pequeño tonelaje', con una africación de la dental sorda y enfatización del segundo término por la vocal adyacente. Al estar en un puerto grande, los contactos con los buques industriales y pescadores de diferentes regiones de Marruecos son mayores. 
poliğa 'polea': tanto El Yaâcoubi (1996: E-118) como Brunot (1920b: 11) le atribuyen un origen español, pero la presencia de la africada sonora sólo se puede explicar por un catalanismo, politja en catalán.

poțera 'potera': un arte de anzuelo de mano para pescar calamares que le debe su nombre a este animal en catalán, pota.

qarroča 'garrucha'.

qəšra pl. qšor, qšur; dim. qšira 'boya': un término polisémico que denomina la corteza y el corcho, se ahí que se utilice para la boya aunque en la actualidad no son de corcho (Brunot 1920b: 111; Dozy 1927: II/349).

šaYra 'sedal' (Brunot 1920b: 70).

šəbbak 'barca': Prémare et al. (1995: VII/22) no incluye la acepción de embarcación. En cambio, Dozy (1927: 1/723) sí lo hace.

šabka pl. šbək 'redes' (Prémare et al. 1995: VII/21; Dozy 1927: I/722).

șənnara pl. șnanar 'anzuelo' (Brunot 1920b: 80; Prémare et al. 1996: VIII/111).

loxa 'lonja': un préstamo reciente dado que es una nueva realidad en la región, tenemos una adaptación fonológica similar a la que suelen presentar los galicismos, la pérdida de la nasal: on $\rightarrow$ o (Heath 1989: 82).

\mal: las redes de pesca en su conjunto (Dozy 1927: II/175).

riparasyon 'reparación' (El Yaacubi 1996: E-38).

pantura: pintura con alquitrán para las embarcaciones (Prémare et al. 1993: 1/311; Brunot 1920b: 13).

\section{Conclusiones}

Tras el análisis de esta muestra del vocabulario pesquera de Targha y Rincón, se puede afirmar que estamos ante un vocabulario muy heterogéneo, que como se ha venido apuntando, es el fruto del contacto lingüístico entre los pescadores mediterráneos que por necesidad, pero también por prestigio y hegemonía, fueron adoptando términos foráneos. Ésta es la principal característica del léxico que utilizan en la actualidad los pescadores del norte de Marruecos. El objetivo de esta pequeña 
aproximación ha sido intentar contribuir a su estudio y poner en valor el patrimonio oral de estos animosos pescadores que mantienen un oficio de mar, en uno moribundo.

En general, se puede agrupar el vocabulario pesquero empleado por los pescadores del norte de Marruecos en cuatro grupos: 1) préstamos andalusíes de origen latino; 2) palabras de la lingua franca; 3) hispanismos; y 4) galicismos que llegan a través de los pescadores que faenan en los grandes buques pesqueros de la costa atlántica aunque estos últimos aún son muy escasos en esta región y todavía no forman parte de la jerga pesquera. En cambio, hay muestras de una tendencia de cambio ya que algunos pescadores recurrieron a términos de origen francés para informarnos de otros usos que seguramente se irán adoptando gracias al contacto con otros pescadores y turistas de otras regiones de Marruecos en cuyas hablas hay una mayor presencia del francés, tanto por el uso de la alternancia de códigos como de galicismos (Ennaji 2005).

Por el contrario, el vocabulario técnico es mucho más uniforme y los préstamos del español muestran menos alteraciones, lo que denota que ha habido y hay ciertos niveles de bilingüismo en la región (Sayahi 2011: 86). Sin embargo, es un vocabulario más inestable dado que los pescadores varían levemente su pronunciación mientras que en el caso de los ictiónimos, los préstamos ya forman parte del vocabulario de base de la región.

La pesca artesanal es una actividad en regresión. Por tanto, el vocabulario empleado por los pescadores, tan heterogéneo e interesante, también va a ir cambiando y desapareciendo a medida que vaya industrializándose el sector, por lo que es un momento idóneo para volver sobre la ictionimia y las artes de la pesca en el norte de Marruecos cuyo estudio se ha de abordar desde diferentes enfoques: lingüístico y social. Gracias a su riqueza en préstamos nos puede aportar mucha información sobre el contacto lingüístico en el Mediterráneo, incorporar préstamos al árabe marroquí y también profundizar en los diferentes mecanismos para incorporar préstamos del árabe marroquí. 


\section{Referencias}

Alvar, M. (1970) "Ictionimia y geografía lingüística”, Revista de Filología Española, 53, 1/4. <http://xn--revistadefilologiaespaola-uoc.revistas.csic.es/index.php/rfe/article/view/784 /910>

AnAya Revuelta, I. (1999) La definición enciclopédica: estudio del léxico ictionímico, Madrid: Consejo Superior de Investigaciones Científicas.

BAzZANA, A. et al. (1991) "Archéologie et peuplement : les mutations médiévales, le cas de Targha”, en A. Zoyggari \& J. Vignet-Zunz (dirs.), Jbala-Histoire et société. Études sur le Maroc du nord-ouest, París/Casablanca: Wallada/CNRS, 307-329.

BELloc, G. (1934) "Catalogue des Poissons comestibles du Maroc et de la Côte occidentale d'Afrique (du Cap Sorel au Cap Vert), Première partie. - Poissons cartilagineux", Revue des Travaux de l'Institut des Pêches Maritimes, 7/2, 117-193.

BEHNSTEDT, P. (2002) "La frontera entre el bereber y el árabe en el Rif”, Estudios de Dialectología Norteafricana y Andalusí, 6, 10-11.

BRUNOT, L. (1920a) La mer dans les traditions et les industries à Rabat \& Salé, París: E. Leroux.

BRUNOT, L. (1920b) Notes lexicologique sur le vocabulaire maritime de Rabat \& Salé, París: E. Leroux.

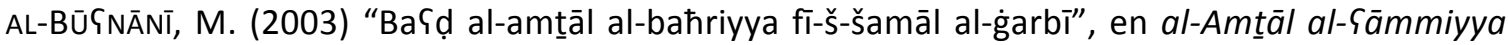
fi-I-Mag̉rib. Tadwīnu-ha wa-tawẓîfu-ha al-Silmī wa-I-bīdāg்ūğī, Rabat: Akādīmiyyat alMamlaka al-Maǵribiyya, 467-477.

CAMPS, G. y J. VIGNEZ-ZUNZ (1998) "Ghomâra”, Encyclopédie berbère 20. [En línea]. Consultado el 14 de febrero de 2015: <http://encyclopedieberbere.revues.org/1923>.

CORRIENTE, F. (1981) “Notas de lexicología hispano-árabe (III y IV)", Awraq: Estudios sobre el mundo árabe e islámico contemporáneo, 4, 5-30.

CORRIENTE, F. (1997) A dictionary of Andalusi Arabic, Leiden/Nueva York/Colonia: Brill.

CORRIENTE, F. (2008) Dictionary of Arabic and Allied Loanwords: Spanish, Portuguese, Catalan, Gallician and Kindred Dialects, Leiden: Brill.

CORRIENTE, F. (2011) A Descriptive and Comparative Grammar of Andalusi Arabic, Leiden/Nueva York/Colonia: Brill.

DAKHLIA, J. (2008) Lingua franca. Histoire d'une langue métisse en Méditerranée, Arles: Actes Sud.

DozY, R.P.E. (1927) Supplément aux dictionnaires arabes, 2a ed., 2 vols. Leiden/París: J. E. Brill/Librairie Orientale et américaine Maisoneuve Frères. 
EL YAÂCOUBI, M. (1996) La influencia léxica del árabe andalusí y del español moderno en el árabe dialectal marroquí, Tesis Doctoral, Universidad Autónoma de Madrid, Facultad de Filosofía y Letras, Departamento de Estudios Árabes e Islámicos.

ENNAJ, M. (2005) Multilingualism, cultural identity and education in Morocco, Nueva York: Springer.

FAO COPEMED. [En línea]. Consultado el 24 de octubre de 2014: <http://www.faocopemed.org/old_copemed/reports/artfish/artfiweb/mar/ports/martar dp2.html>.

GonzÁlez García, E. (2008) Motivación y creación léxica en las hablas populares, Tesis Doctoral, Universidad Complutense de Madrid, Facultad de Filología, Departamento de Filología Española.

GuerRero PARRADO, J. (2015) El dialecto árabe hablado en la ciudad marroquí de Larache, Zaragoza: Prensas de la Universidad de Zaragoza.

HEATH, J. (1989) From Code-switching to Borrowing: Foreign and Diglossic mixing in Moroccan Arabic, London/Nueva York: Kegan Paul International.

ICTIOTERM <http://www.ictioterm.es/bibliografia.php>.

JolY, A. (1912) “L'industrie à Tétouan (Suite)”, Archives marocaines, XVIII, 187-256.

KAddour, A. (2013) Contribución al estudio de los hispanismos en el oeste de Argelia: corpus léxico, análisis fonético, morfológico y semántico, Tesis Doctoral, Universidad Complutense de Madrid, Facultad de Filología, Departamento de Lengua Española y Teoría de la Literatura y Literatura Comparada.

KAHANE, H. et al. (1953) "El término mediterráneo faluca", Nueva revista de Filología Hispánica, $7 / 2,56-62$.

LAOUST, E. (1923) "Pêcheurs berbères du Sous", Hespéris, 3, 237-364.

LATAOUI, A. (2000) Ichtyonymie marocaine: étude historico-linguistique des noms des poissons marins au Maroc, Rabat: Faculté des lettres et des sciences humaines.

LEÓN EL AfRICANo (1830) De l'Afrique contenant la description de ce pays, París: Imprimé aux frais du Gouvernement.

LÉVY, S. (1992) "Ports, parlers portuaires et importation linguistique", en A. Kaddouri (coord.), Le Maroc et l'Atlantique, Rabat: Publications de la Faculté des Lettres et des Sciences Humaines, 59-74.

LouIS, A. (1977) “Apports espagnols dans le vocabulaire maritime des côtes marocaines, apports italiens dans celui de des côtes tunisiens: comparaison entre quelques termes de 
batellerie, de manœuvre et de pêche", en M. Alvar (ed.), Terminología marinera del Mediterráneo, Madrid: Consejo Superior de Investigaciones Científicas, 27-40.

MARÇAIS, W. (1911) Textes arabes de Tanger. Transcription, traduction annotée et glossaire, París: Imprimerie Nationale.

Martín CoRrales, E. (2000) "La pesca española en el Magreb (ss. XVI-XVIII)", en G. Doneddu \& M. Gangemi (eds.), La pesca nel Mediterraneo occidentale, Bari: Puglia Grafica, 9-38.

MARTín CORRALES, E. (2001) Comercio de Cataluña con el mediterráneo musulmán (siglos XVIXVIII): El comercio con los "enemigos de la fe", Barcelona: Bellaterra.

MondÉJAR, J. (1989) "Robalo y lubina (Morone Labrax L.). Otro capítulo de ictionimia mediterránea y atlántica", Revista de filología española, LXIX/2, 61-95.

MontAgne, R. (1923) “Les marins indigènes de la zone française du Maroc", Hespéris, 3, 175-216.

MontAgne, R. (1924) “Coutumes et légendes de la côte berbère du Maroc", Hespéris, 4, 101-116.

OMAN, G. (1966) L'ittionimia nei paesi Arabi del Mediterraneo, Florencia: Casa editrice Leo S. Olschki.

PAMIES, A. (2010) "El componente (inter)cultural en la metáfora: el caso de la ictionimia", C. Crida Álvarez (ed.), Freseo-paremiología e interculturalidad, Atenas: Ta Kalos Keimena, 3353.

PrÉmARE, E. et al. (1993-1999) Dictionnaire arabe-français: établi sur la base de fichiers, ouvrages, enquêtes, manuscrits études et documents divers, París: L'Harmattan.

Roullot, J. et al. (1984) Catalogue des engins de pêche au Maroc [En línea]: <http://www.faocopemed.org/old_copemed/reports/artfish/artfiweb/mar_main.html> (Consultado el 24 de octubre de 2014).

SAYAHI, L. (2011) "Contacto y préstamo léxico: el elemento español en el árabe actual", Revista Internacional de Lingüística Iberoamericana, IV, 85-99.

SIMONET, F.J. (1888) Glosario de voces ibéricas y latinas usadas entre los mozárabes, Madrid: Establecimiento tipográfico de Fortanet.

TRECCANI L'Enciclopedia Italiana [en línea]: <http://www.treccani.it/enciclopedia/>.

VIGNEZ-ZUNZ, J. (1995) “Djebala”. Encyclopédie berbère, 16. [En línea] consultado el 14 de febrero de 2015: <http://encyclopedieberbere.revues.org/2176>. 